\title{
Emerging electromagnetic interferences between implantable cardioverter-defibrillators and left ventricular assist devices
}

\author{
Yunus C. Yalcin ${ }^{1,2}$, Claudette Kooij ${ }^{1}$, Dominic A.M.J. Theuns ${ }^{2}$, \\ Alina A. Constantinescu ()$^{1}$, Jasper J. Brugts ()$^{1}{ }^{1}$, Olivier C. Manintveld ()$^{1}$, \\ Sing-Chien Yap ${ }^{1}$, Tamas Szili-Torok $\mathbb{1}{ }^{1}$, Ad J.J.C. Bogers $\mathbb{1}^{2}{ }^{2}$, and \\ Kadir Caliskan (1D) ${ }^{1 *}$
}

${ }^{1}$ Department of Cardiology, Erasmus MC University Medical Center, Room RG 431, Dr Molewaterplein 40, Rotterdam, The Netherlands; and ${ }^{2}$ Department of Cardio-thoracic Surgery, Erasmus Medical Center, 3015 GD Rotterdam, The Netherlands

Received 26 September 2019; editorial decision 18 December 2019; accepted 13 January 2020; online publish-ahead-of-print 31 January 2020

Aims

To investigate the prevalence of electromagnetic interference (EMI) between left ventricular assist devices (LVADs) and implantable cardioverter-defibrillators (ICDs)/pacemakers (PMs).

Methods

and results

A retrospective single-centre study was conducted, including all patients undergoing HeartMate II (HMII) and HeartMate $3(H M 3)$ LVAD implantation $(n=106)$. Electromagnetic interference was determined by the inability to interrogate the ICD/PM. Overall, 85 (mean age $59 \pm 8,79 \%$ male) patients had an ICD/PM at the time of LVAD implantation; 46 patients with HMII and 40 patients with HM3. Among the 85 LVAD patients with an ICD's/PM's, 11 patients (13\%) experienced EMI; 6 patients (15\%) with an HMII and 5 patients (11\%) with an HM3 $(P=0.59)$. Electromagnetic interference from the HMII LVADs was only present in patients with a St Jude/Abbott device; 6 of the $23 \mathrm{St}$ Jude/Abbott devices. However, in the HM3 patients, EMI was mainly present in patients with Biotronik devices: 4 of the 18 with only one (1/25) patient with a Medtronic device. While initial interrogation of these devices was not successful, none of the 11 cases experienced pacing inhibition or inappropriate shocks.

Conclusion In summary, the prevalence of EMI between ICDs in the older and newer type of LVAD's remains rather high. While HMII patients experienced EMI with a St Jude/Abbott device (which was already known), HM3 LVAD patients experience EMI mainly with Biotronik devices. Prospective follow-up, preferably in large registries, is warranted to investigate the overall prevalence and impact of EMI in LVAD patients.

Keywords

Left ventricular assist device - Implantable cardioverter-defibrillator • Pacemaker - End-stage heart failure - Electromagnetic interference

\section{Introduction}

Left ventricular assist device (LVAD) therapy is increasingly utilized to treat end-stage heart failure patients who are in dire need of circulatory support. ${ }^{1}$ Most patients who are eligible for continuous-flow LVAD therapy, already have an implantable cardioverter-defibrillator
(ICD) and/or pacemaker (PM) implanted. ${ }^{1}$ However, following LVAD implantation, electromagnetic interference (EMI) can occur between the LVAD and the ICD/PM. Recently, multiple cases of EMI between LVADs and ICD's/PM's have been reported. ${ }^{2-4}$ The EMI hinders the interrogation of the ICD/PM's and leaves clinicians in the dark. Therefore, the aim of the present study was to investigate the

\footnotetext{
* Corresponding author. E-mail address: k.caliskan@erasmusmc.nl

(c) The Author(s) 2020. Published by Oxford University Press on behalf of the European Society of Cardiology.

This is an Open Access article distributed under the terms of the Creative Commons Attribution Non-Commercial License (http://creativecommons.org/licenses/by-nc/4.0/), which permits non-commercial re-use, distribution, and reproduction in any medium, provided the original work is properly cited. For commercial re-use, please contact journals.permissions@oup.com
} 


\section{What's new?}

- Left ventricular assist device (LVAD) therapy is increasingly utilized to treat end-stage heart failure patients. However, following LVAD implantation, electromagnetic interference (EMI) can occur, in this study mainly between HeartMate 3 and Biotronik ICD devices.

- Following a stepwise approach could enable interrogation of the ICD/PM; however, in some cases surgical repositioning is necessary.

prevalence of EMI between different types of ICD/PM in patients implanted with HeartMate II (HMII) and the recently introduced HeartMate 3 (HM3).

\section{Methods}

\section{Study design}

We reviewed all patients who received an LVAD between December 2006 and February 2019 in our tertiary referral centre with a prior ICD/ PM implantation or device replacement due to end-of-life. The study was approved by the institutional review board of the Erasmus MC Medical Centre Rotterdam.

\section{Endpoints}

The primary outcome was the occurrence of EMI, defined as ICD/PM telemetry interference (i.e. the inability to interrogate ICD/PM).

\section{Data collection}

All data were obtained from the electronic patient records. Baseline characteristics were collected pre-operatively for all patients. Devices included were the HMII, HM3 (Abbott, IL, USA).

\section{Statistical analysis}

Continuous parameters are expressed as median and inter-quartile range or mean and standard deviation, depending on the distribution. Categorical parameters were expressed as number and percentage and compared by $\chi^{2}$ test. Analyses were performed using the SPSS statistical software package, version 24.0 for Mac (SPSS Inc., IBM Company, Chicago, IL, USA).

\section{Results}

In total, 109 patients received an LVAD (mean age at implantation $52 \pm 12,83 \%$ male). Overall, 86 (mean age $59 \pm 8,79 \%$ male) patients had an ICD $(n=85)$ or PM $(n=1)$ at the time of LVAD implantation; 46 patients with $\mathrm{HMII}$ and 40 with $\mathrm{HM}$. One patient with an ICD was excluded from further analysis because of missing follow-up data. None of the ICDs/PMs showed any abnormalities prior to the LVAD implantation. The implanted ICD/PM devices were from Medtronic (Dublin, Ireland) ( $n=25)$, St Jude/Abbott (Chicago, IL, USA) $(n=23)$, Biotronik (Berlin, Germany) $(n=18)$, Boston Scientific (Marlborough, MA, USA) $(n=18)$, and Microport (Shanghai, China) $(n=1)$ (see Figure 1). Among the 85 LVAD patients with an ICD's/PM's, 11 patients (13\%) experienced EMI; 6 ICD patients (15\%) with an HMII and 5 ICD patients $(11 \%)$ with an $\mathrm{HM} 3(P=0.59)$.

Electromagnetic interference from the HMII LVADs was only present in patients with a St Jude/Abbott device; 6 of the 23 St Jude/ Abbott devices (1 Atlas, 1 Unify, 1 Fortify, 1 Elipse, and 2 Promote). However, in the HM3 patients, EMI was mainly present in patients with Biotronik devices: 4 of the 18 (device types: Lumax, llivia, llesto, and lperia) with only one (1/25) patient with a Medtronic (Claria) device (see Table 1 for complete overview). None of the PM patients showed any signs of EMI.

\section{Clinical outcomes}

In 4 out of 11 patients, interrogation could not be performed in any form. For the other seven patients, with some minor adjustments, interrogation was made possible. While initial interrogation of these devices was not successful, none of the 11 cases experienced pacing inhibition or inappropriate shocks.

\section{Discussion}

The current study was aimed to gain insight on the prevalence of EMI between the HMII and HM3 LVAD's and several ICD/PM device types. The principal findings are as follows: (i) EMI is present in $13 \%$ of LVAD patients with ICD's in situ. (ii) In patients with an HMII, EMI is present only when they had an ICD from St Jude/Abbott implanted. However, in HM3 LVAD patients, EMI was mainly present in patients with ICD's from Biotronik. (iii) While 11 patients presented with difficulties regarding interrogation of their ICD, none of the patients experienced pacing inhibition or inappropriate shocks.

Currently, the LVAD literature mainly describes EMI in patients with a St Jude/Abbott device. Yet in the more recent HM3 type LVADs, it almost exclusively occurred in patients who had received a Biotronik device. Recently, several reported cases noticed the occurrence EMI between a Biotronik ICD and an HM3 LVAD. ${ }^{2-4}$ This emerging phenomenon warrants increased vigilance as an increasing number of patients receive HM3 LVAD therapy. Of note, since in our single cohort, no pacing inhibition or inappropriate shock has been administered, the clinical implication of the phenomenon appears limited. However, in larger cohorts with longer follow-up and/or emergency settings, the recognition of this phenomenon, the possible following complications and subsequent appropriate approach of EMI between ICD and LVAD could be of paramount importance.

The occurrence of EMI most likely occurs due to the magnetic components of the HMII and HM3 LVAD's, which hinder the interrogation of the ICD. The use of radiofrequency (RF), which is not affected by EMI, could be used to bypass this issue. Therefore, activating the RF use prior to LVAD implantation (if possible) should be considered. In patient with an LVAD in situ this is no longer is an option. Nonetheless, RF use can be beneficial. However, to activate the RF use, initial contact with the ICD is required. To achieve this, it seems that the distance between the ICD and the LVAD must be increased. Raising the ipsilateral arm and/or raising the ICD in its pocket can create enough distance to enable RF use. Alternatively, a Faraday cage (using copper or iron plates) can be put over the area with the LVAD to minimize EMI and enable RF use. Unfortunately, in some 
Table I Electromagnetic interferences between implantable cardioverter-defibrillators and left ventricular assist devices observed in study population

\begin{tabular}{|c|c|c|c|c|c|c|c|}
\hline Patient & $\begin{array}{l}\text { ICD } \\
\text { manufacturer }\end{array}$ & Type & $\begin{array}{l}\text { LVAD } \\
\text { type }\end{array}$ & Indication & $\begin{array}{l}\text { Support } \\
\text { duration }\end{array}$ & Type of EMI & Intervention \\
\hline 1 & St Jude Medical & Unify (CRT-D) & HMII & Bridge-to-transplantation & 25 days & $\begin{array}{l}\text { Interference with telemetry } \\
\text { function }\end{array}$ & RF use \\
\hline 2 & St Jude Medical & Elipse (ICD) & HMII & Bridge-to-transplantation & 203 days & $\begin{array}{l}\text { Interference with telemetry } \\
\text { function }\end{array}$ & $\begin{array}{l}\text { No interrogation } \\
\text { possible }\end{array}$ \\
\hline 3 & St Jude Medical & Atlas (ICD) & HMII & Bridge-to-transplantation & 287 days & $\begin{array}{l}\text { Interference with telemetry } \\
\text { function }\end{array}$ & $\begin{array}{l}\text { No interrogation } \\
\text { possible }\end{array}$ \\
\hline 4 & St Jude Medical & Fortify (ICD) & HMII & Bridge-to-transplantation & 970 days & Dysfunction ICD system ${ }^{a}$ & Device replacement \\
\hline 5 & St Jude Medical & Promote (CRT-D) & HMII & Bridge-to-transplantation & 1061 days & $\begin{array}{l}\text { Interference with telemetry } \\
\text { function }\end{array}$ & RF use \\
\hline 6 & St Jude Medical & Promote (CRT-D) & HMII & Bridge-to-transplantation & 1886 days & $\begin{array}{l}\text { Interference with telemetry } \\
\text { function }\end{array}$ & RF use \\
\hline 7 & Biotronik & Ilesto (CRT-D) & $\mathrm{HM} 3$ & Bridge-to-decision & 199 days & $\begin{array}{l}\text { Interference with telemetry } \\
\text { function }\end{array}$ & $\begin{array}{l}\text { Patient in lying } \\
\text { position }\end{array}$ \\
\hline 8 & Medtronic & Viva (CRT-D) & $\mathrm{HM} 3$ & Bridge-to-transplantation & 275 days & $\begin{array}{l}\text { Interference with telemetry } \\
\text { function }\end{array}$ & $\begin{array}{l}\text { No interrogation } \\
\text { possible }\end{array}$ \\
\hline 9 & Biotronik & Iperia (CRT-D) & HM3 & Destination therapy & 348 days & $\begin{array}{l}\text { Interference with telemetry } \\
\text { function }\end{array}$ & Uplift device \\
\hline 10 & Biotronik & Ilivia (CRT-D) & HM3 & Bridge-to-transplantation & 724 days & $\begin{array}{l}\text { Interference with telemetry } \\
\text { function }\end{array}$ & $\begin{array}{l}\text { No interrogation } \\
\text { possible }\end{array}$ \\
\hline 11 & Biotronik & Lumax (ICD) & HM3 & Bridge-to-transplantation & 997 days & $\begin{array}{l}\text { Interference with telemetry } \\
\text { function }\end{array}$ & $\begin{array}{l}\text { Patient in lying } \\
\text { position }\end{array}$ \\
\hline
\end{tabular}

CRT-D, cardiac resynchronization therapy defibrillator; EMI, electromagnetic interference; HM, HeartMate; ICD, implantable cardioverter-defibrillator; LVAD, left ventricular assist device; RF, radiofrequency.

${ }^{a}$ After implantation of the LVAD, the ICD device appeared to be in back-up mode (VVI 65 bpm) and shock therapy was disabled. After a multidisciplinary consultation (together with Abbott), it was decided to replace the ICD device. The cause of this problem was attributed to the EMI generated by the implanted HMII. Following the replacement with a device from a different manufacturer, no further issues were observed.

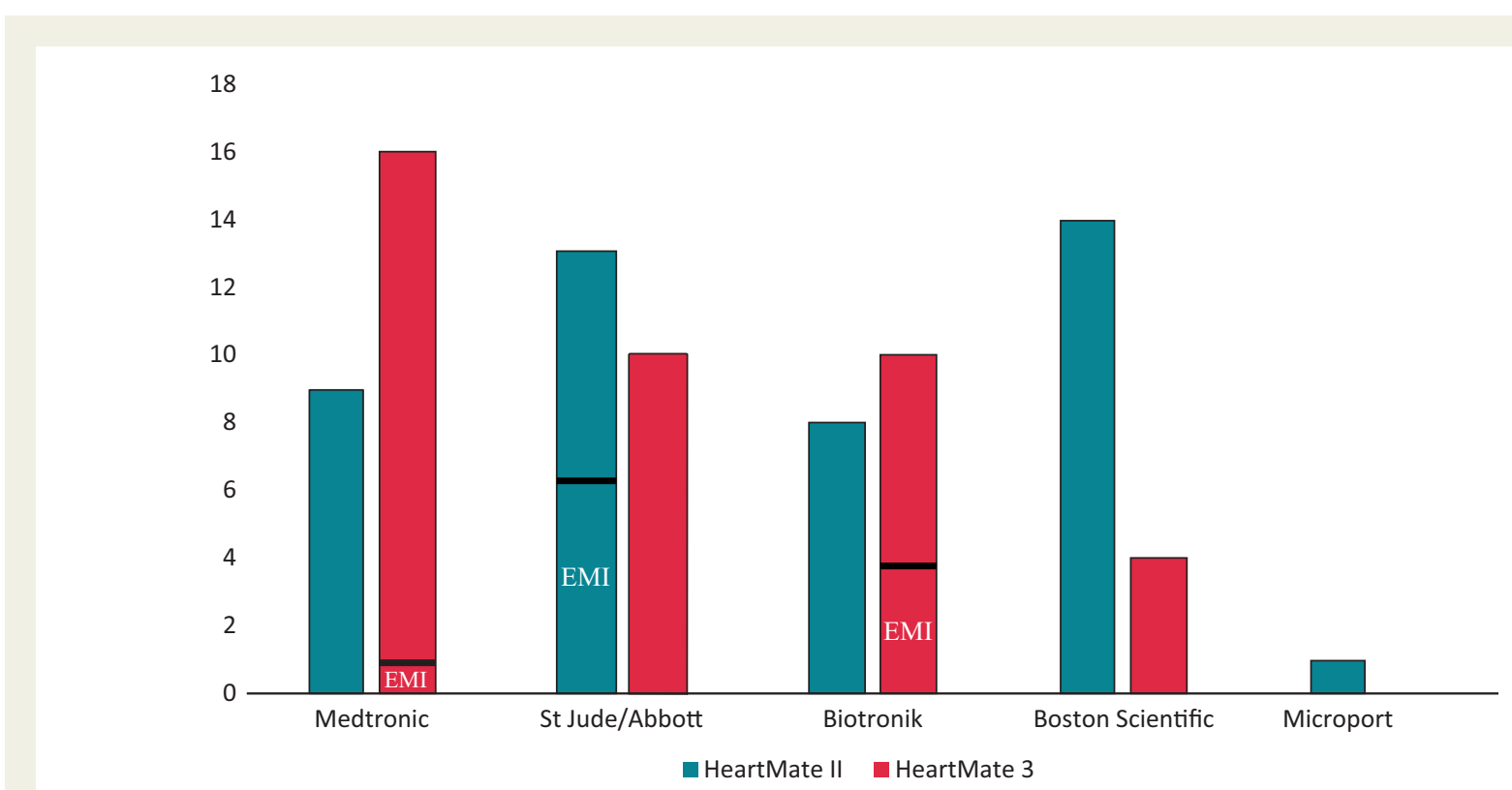

Figure I Cardiac implantable electronic device manufacturer distribution among the HeartMate II and HeartMate 3 left ventricular assist device types. HM, HeartMate. 


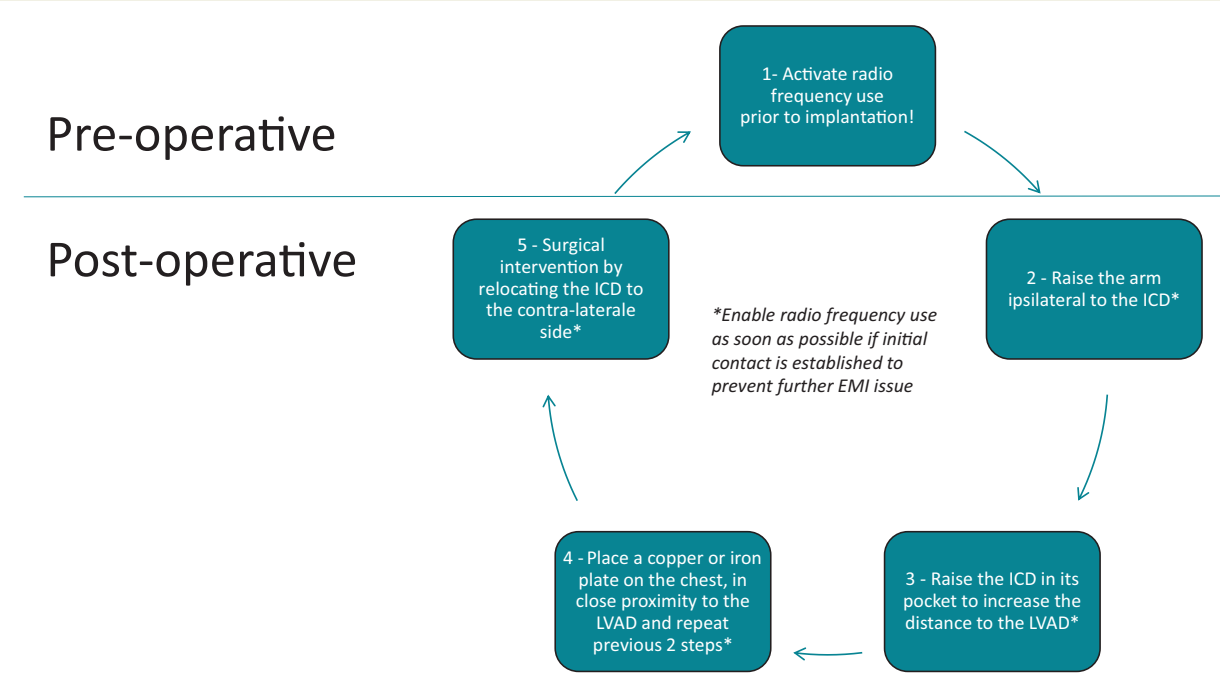

Figure 2 A stepwise approach to reduce the occurrence and impact of electromagnetic interference in left ventricular assist device patients.

cases, these methods were insufficient, and the ICD could not be interrogated. These situations could benefit from surgical intervention to increase the distance between both devices. This could be done by implanting the ICD in the contra-lateral side (see Figure 2 for complete overview). While no pacing inhibition took place or inappropriate shocks were administered, the EMI between the LVAD and the ICD hampers optimal ICD therapy. As this is a retrospective study, to further elucidate the effect of EMI between the contemporary HM3 LVAD and ICDs, prospective registries like the interagency registry for mechanically assisted circulatory support (INTERMACS) and the European registry for patients with mechanical circulatory support (EUROMACS) should incorporate these findings.

\section{Conclusion}

In summary, the prevalence of EMI between ICDs in the older and newer type of LVAD's remains rather high. While HM2 patients experienced EMI with a St Jude/Abbott device (which was already known), in our single-centre cohort, the HM3 LVAD patients experience EMI mainly with Biotronik devices. Ensuring enough distance between the ICD and the LVAD seems to be beneficial. The provided methods can aid clinicians who experience similar problems with the interrogation of the ICD of their LVAD patients. While the aforementioned options to bypass this issue exist, they are sometimes inadequate. We, therefore, recommend further research, preferably conducted via prospective multicentre registries, to elucidate the full extent of the currently observed issue.

Conflict of interest: none declared.

\section{References}

1. Kormos RL, Cowger J, Pagani FD, Teuteberg JJ, Goldstein DJ, Jacobs JP et al. The Society of Thoracic Surgeons Intermacs database annual report: evolving indications, outcomes, and scientific partnerships. J Heart Lung Transplant 2019;38:114-26.

2. Schukro C, Schloglhofer T, Khazen C, Rohrich M, Laufer G, Zimpfer D et al. Influence of a fully magnetically levitated left ventricular assist device on functional interrogation of implantable cardioverter defibrillators. Clin Cardiol 2019; 42:914-8.

3. Duncker D, König T, Müller-Leisse J, Michalski R, Oswald H, Schmitto JD et al. Electric smog: telemetry interference between ICD and LVAD. Herzschr Elektrophys 2017;28:257-9.

4. Sehatbakhsh S, Kushnir A, Kabach M, Kolek M, Chait R, Ghumman W. A case of electromagnetic interference between HeartMate 3 LVAD and implantable cardioverter defibrillator. Pacing Clin Electrophysiol 2018;41:218-20. 